\title{
Dissociation of implicit and explicit memory tests: Effect of age and divided attention on category exemplar generation and cued recall
}

\author{
MICHEL ISINGRINI, FLORENCE VAZOU, and PHILLIPE LEROY \\ Université de Tours, Tours, France
}

\begin{abstract}
In this article, we report an experiment that provides further evidence concerning the differences between explicit and implicit measures of memory. The effects of age and divided attention on the implicit conceptual test of category exemplar generation (CEG) were compared with their effects on the explicit test of cued recall, where the category names served as cues in both tasks. Four age groups (20-35, 40-55, 60-75, and 76-90) were compared. Half of the subjects were also required to carry out a secondary letter-detection task during the learning phase. Cued recall performance was significantly impaired by increased age and imposition of the secondary task. In contrast, the CEG task was unaffected by these two factors. These results suggest that implicit conceptual tasks and explicit memory tasks are mediated by different processes. This conclusion opposes those of previous studies that showed that experimental manipulations (level of processing, generation, organization) influenced these two kinds of memory tests in a similar way.
\end{abstract}

In recent years, a large body of research has focused on the distinction between implicit and explicit memory tasks. Explicit memory tasks refer to test procedures that require subjects to reflect consciously on a previous learning episode (e.g., free recall, cued recall, recognition). Implicit memory tasks, in contrast, are defined as tests that do not require conscious recollection of a prior learning episode (e.g., perceptual identification, fragment or stem completion tasks). In this type of test, subjects perform a task that indirectly reveals retention of the stimuli. The effect of prior experience is manifested by better performance on old items than on new ones. This facilitation has been called repetition priming. Interest in priming tasks has increased as a result of several studies showing that performance on tests of implicit and explicit memory can be dissociated (for reviews, see Schacter, 1987; Richardson-Klavehn \& Bjork, 1988). Studies of patients with organic amnesia have provided evidence of such a dissociation. Amnesic patients who are severely impaired on standard explicit memory tasks show normal priming on implicit memory tests (Jacoby \& Witherspoon, 1982; Moscovitch, 1982; Shimamura \& Squire, 1984; Warrington \& Weiskrantz, 1970). Additional support for the dissociation of these two kinds of memory test has been provided by experimental manipulations. Various studies have shown that implicit memory tasks are generally unaffected by elaborative-semantic encoding operations that facilitate performance on explicit

The authors thank Geoffrey Loftus and an anonymous reviewer of an earlier version of this article for helpful comments. Correspondence should be addressed to M. Isingrini, Laboratoire de Psychologie Expérimentale, Université de Tours, 3 rue des Tanneurs, 37000 Tours, France. memory tasks (e.g., level of processing, generation; Graf \& Mandler, 1984; Jacoby \& Dallas, 1981; Roediger \& Blaxton, 1987).

The above results have led some authors to claim that such a dissociation between explicit and implicit memory tests occurs because these two types of task require different modes of processing during encoding and retrieval (Graf \& Mandler, 1984; Roediger, Weldon, \& Challis, 1989).

However, a distinction was made more recently between two forms of implicit tests: a perceptual one (used in the studies presented above) and a conceptual one. Perceptual priming refers to tests where the stimulus presented during the learning phase occurs in a perceptually related, although degraded or partial, form during the test phase. For these measures of memory, people may be asked to complete a word when given some of its letters (word fragment completion task; see Tulving, Schacter, \& Stark, 1982), produce a word that begins with certain letters (word stem completion task; see Graf \& Mandler, 1984), perform a lexical decision task (Scarborough, Cortese, \& Scarborough, 1977), or read visually degraded words (Moscovitch, Winocur, \& McLachlan, 1986). Prior experience has an effect if a word fragment or a word stem is more likely to be completed as a word that had been studied, and if the lexical decision or the visually degraded word identification is facilitated by prior presentation. In contrast, implicit conceptual tests provide information that is conceptually related to the studied information but has no perceptual similarities. In these tasks, subjects are asked to spontaneously produce words when given a highly associated word (free association task; see Shimamura \& Squire,1984), or when given a category name (category association task; category exemplar generation task; see Gardner, Boller, Moreines, \& 
Butters, 1973). A priming effect occurs if the words produced by the subject are more often words previously seen in the study list. Because there are no shared perceptual features between the study and the test condition in conceptual priming, these tasks require substantial semantic processing of the to-be-primed item before a priming effect is produced.

The distinction between these two kinds of implicit test is supported by the finding that some experimental manipulations have a dissociating effect on the perceptual versus conceptual form of implicit tests. Researchers have reported that, similar to explicit tasks, encoding elaboration (like level of processing, generation, and organization) influences priming on conceptual tests (Hamann, 1990; Rappold \& Hastroudi, 1991; Srinivas \& Roediger, 1990). These findings suggest that conceptual priming tests and explicit tests are mediated by similar processes, which are different from those involved in perceptual priming tests (Roediger et al., 1989).

The purpose of the present experiment was to explore these processes by attempting to find out whether conceptual repetition priming tests, like explicit tests, make demands on cognitive resources. To achieve this, we examined the effects of two factors, age and divided attention during encoding, on an explicit cued recall task and on an implicit category exemplar generation (CEG) task (which is in conceptual form). The finding that conceptual priming tasks, like explicit tasks, appear to be dependent on semantic elaboration suggests that these tasks require substantial cognitive resources at encoding time. Consequently, one may hypothesize that experimental manipulation of factors, such as age and divided attention, which are known to deplete cognitive resources, may affect performance on conceptual priming tests and explicit tests in a similar manner.

Although it is well known that age-related memory deficits are observed on explicit tasks, there is good evidence that age differences in memory are much smaller or even eliminated in various implicit perceptual tests (Light \& La Voie, 1993). In the majority of cases, studies have demonstrated that old and young subjects show comparable priming effects on word completion tests (Java \& Gardiner, 1991; Light \& Singh, 1987; Light, Singh, \& Capps, 1986), word identification tests (Light \& Singh, 1987; Moscovitch, 1982), reading tests (Moscovitch et al., 1986), and picture naming tests (Mitchell, 1989; Mitchell, Brown, \& Murphy, 1990). It is also known that the type of learning that supports performance on recall and recognition tests requires the availability of some attentional resources. If subjects are engaged in a concurrent attentiondemanding task when list items were available for inspection, their subsequent performance on an explicit episodic task is much lower than that under full-attention conditions. In contrast, studies have shown that concurrent processing tasks have no effect on perceptual repetition priming (Parkin, Reid, \& Russo, 1990; Parkin \& Russo, 1990; Smith \& Oscar-Berman, 1990). Manipulations of age and divided attention have suggested that perceptual repetition priming is not dependent on the al- location of attention. It therefore seems to be of theoretical interest to determine whether this observation could be generalized to conceptual repetition priming.

However, there may be a decline in performance on conceptual priming tasks with age and divided attention. There is evidence of an age-related decrease in the degree to which older people engage in semantic elaboration of material to be memorized. An age $\times$ level of processing interaction showing that elderly adults benefit less from the deeper level of processing was first reported by Eysenck (1974) and White (cited by Craik, 1977). On the other hand, some authors (Craik, 1986; Craik \& Byrd, 1982; Hasher \& Zacks, 1979) have suggested that, when compared with young adult controls, elderly adults show declines on cognitive tasks due to a diminished pool of mental energy that governs effortful cognitive processes. Age differences become manifest on cognitive tasks that require substantial cognitive resources or self-initiated processing. Therefore, putting together what is known about aging, and the fact that CEG tasks (unlike implicit perceptual tasks) appear to be semantic-elaboration-dependent, suggests that this task may be sensitive to age. For similar reasons, it can be hypothesized that conceptual priming is affected by divided attention, which is also likely to induce depletion of cognitive resources.

The present experiment extends research on implicit repetition conceptual tasks to a previously unexplored domain by examining the effect on CEG of divided attention during learning. With regard to aging, only two studies examining the effect of this factor on conceptual repetition priming have been reported. Because these works have produced conflicting results, it seems of interest to continue research about this question. Using a CEG test, Light and Albertson (1989) clearly showed that comparable priming effects were obtained for young and older adults. However, in a more recent study, including young adults, older adults, and demented subjects, Grober, Gitlin, Bang, and Buschke (1992) found a decrease in performance for normal older adults on a conceptual priming task involving category association, where the category names were also used as cues for target production. These divergent results may be due to differences between these two studies as to the type of procedure used and the age of the older subjects. First, in the study by Light and Albertson, priming was measured by taking the number of targets that appeared in the first eight category members produced, whereas in the category association test used by Grober et al., only the first word produced was taken into account. Second, unlike Light and Albertson, Grober et al. systematically administered the implicit test after the subjects had responded to the explicit task. This procedure may have introduced "contamination" of implicit task performance by explicit retrieval strategies, which was beneficial for young adults. Finally, the mean ages were 69 and 78 years for the Light and Albertson study and Grober et al. study, respectively, suggesting that a decline in conceptual priming may occur in late adulthood. To confirm 
and extend these studies, and in the light of the hypothesis that a decline with age may occur at a later stage of adulthood with the decrease in semantic elaboration and the lesser availability of cognitive resources, we compared the performance of two groups of young subjects (range $=20-35$ and 40-55 years) with two groups of older subjects: older (range $=60-75$ years) and much older (range $=76-90$ years). Our experimental procedure was similar to that used by Light and Albertson (1989).

\section{METHOD}

\section{Design and Subjects}

The experiment included two between-subject factors (age and divided/undivided attention) and one within-subject factor (type of memory test: CEG and cued recall). The design was a 4 (age) $\times 2$ (type of learning) $\times 2$ (type of test) mixed design.

A total of 160 subjects, forming 8 groups of 20 individuals, participated in the experiment. The following four age groups were assigned to the undivided attention condition of learning: G1 (range $=20-35$ years, $M=26, S D=6.08$ ), G2 (range $=40-55$ years, $M=45.90, S D=5.26$ ), $\mathrm{G} 3$ (range $=60-75$ years, $M=$ $67.65, S D=4.67$ ), and $\mathrm{G} 4$ (range $=76 \cdots 90$ years, $M=81.65$, $S D=3.71$ ). The following four age groups were assigned to the divided attention condition of learning: $\mathrm{GS}$ (range $=20-35$ years, $M=26.50, S D=4.61$ ), G6 (range $=40-55$ years, $M=44.75$, $S D=5.38$ ), G7 (range $=60-75$ years, $M=67.45, S D=4.67$ ), and $\mathrm{G} 8$ (range $=76-90$ years, $M=80.20, S D=4.16$ ). To match all groups on verbal ability, the Binois-Pichot 44-item, multiplechoice synonym vocabulary test was administered. The four groups assigned to the simple-task condition scored $21.50(S D=$ $4.04), 21.45(S D=3.20), 21.55(S D=5.16)$, and $21.35(S D=$ 2.99 ) for $\mathrm{G} 1, \mathrm{G} 2, \mathrm{G} 3$, and $\mathrm{G} 4$, respectively. The four groups assigned to the dual-task condition scored $21.40(S D=3.47), 22.40$ $(S D=3.67), 21.65(S D=4.39)$, and $21.55(S D=3.44)$ for $G 5$, G6, G7, and G8, respectively. An analysis of variance (ANOVA) showed that there were no reliable effects across learning conditions $\left[F(1,152)<1, M S_{\mathrm{e}}=14.87\right]$ and no reliable effects across ages $\left[F(1,152)<1, M S_{\mathrm{e}}=14.87\right]$. Each group consisted of 10 males and 10 females. All subjects claimed to be in good health and stated they were not taking any medication likely to affect cognitive behavior. The participants were volunteers and were tested individually.

\section{Materials}

Two study lists of 50 nouns were used equally often in each group. Each list consisted of 32 filler words and 18 targets. The 18 targets were 3 members of 6 taxonomic categories, with different categories represented on each of the two lists. Category members were selected from the least frequent instance generated in Tourette's (1979) category norming study. The mean normative frequencies of the two lists of target were comparable. The fillers were nouns with a mean normative frequency higher than that of target words. The first 4 and last 4 words in each list were fillers. A single random order was used for each list. The 18 target words were randomly interspersed among the fillers. The words were presented in a booklet, with each target item printed in uppercase letters on a $16 \times 6 \mathrm{~cm}$ white page.

\section{Procedure}

As in the Light and Albertson (1989) study, the same general instructions were given at the beginning of the test session for all subjects. The instructions said that the task was designed to provide normative materials for future research. The purpose of this mild deception was to prevent participants from engaging in encoding strategies in anticipation of later retrieval requirements and to encourage them to view later tasks as unrelated to the earlier one, until explicit measures of memory were given. The 50word study list was presented at a rate of $5 \mathrm{sec}$ per item. The participants were asked to look at each word carefully and to rate how pleasant or unpleasant they found the meaning of the word. They responded in writing on a prepared answer sheet using a 5-point scale (ranging from $1=$ very pleasant to $5=$ very unpleasant). No mention was made of any subsequent memory test.

The exemplar generation test was separated from presentation of the study list by the the vocabulary test; 15 min were allocated for the vocabulary test. For exemplar generation, participants were told they would be presented with category names and that they had to write the names of all the things belonging to each category within the given time limit. The category names were presented in a booklet, with one name printed on each page. For a given category, the exemplar generation task lasted $2 \mathrm{~min}$. Six of the 12 categories tested at this time occurred on the study list, and 6 were new categories (occuring on the alternate list) used to obtain baseline rates for CEG when this had not been recently displayed. Priming was measured by counting the number of targets that appeared in the first eight category members produced, and comparing the primed and unprimed categories on this measure. Following the CEG task, there was a 5-min retention interval during which the subjects were engaged in conversation with the experimenter. Finally, a cued recall test was given as an explicit measure of memory. The participants were presented with a sheet listing the names of the six categories represented on their study list and were asked to recall any word they remembered from the study list that belonged to those categories. No time limit was set for this task. The participants were told that the study list contained 3 words from each category, but they were not asked to produce any particular number of words for each category. After the cued recall test, all participants were asked whether, for the exemplar generation test, they had noticed that they were generating previously seen list members and whether they deliberately tried to do so. The subjects who responded "yes" to the last question were eliminated from the experiment.

In the dual-task learning condition, all stimuli and procedures were identical to those employed in the simple-task learning condition described above, except that the participants performed a consonant monitoring task during the study phase. The subjects in this condition listened to a tape containing a series of consonants (selected from a pool of 15 letters) presented at a rate of one per second. Their task was to tell the experimenter whenever a $B$ or a G occurred, while looking at each word on the study list and responding in writing on the pleasant-unpleasant scale. The subjects' responses were recorded on tape (the experimenter discretely recorded the responses). The number of letters correctly detected was not identical across ages, with a mean proportion of $.67(S D=.12)$ for $\mathrm{G} 5(20-35$ years $), .58(S D=.13)$ for $\mathrm{G} 6(40$ 55 years $), .32(S D=.13)$ for $\mathrm{G} 7(60-75$ years $)$, and $.15(S D=$ $.05)$ for G8 (76-90 years). An ANOVA showed a significant effect of age $\left[F(3,76)=82.90, M S_{\mathrm{e}}=136.86, p<.001\right]$. In this experiment, we did not match the groups on the number of detected letters, since we did not set out a precise hypothesis about the age effect with respect to a situation of divided attention; furthermore, we wanted to retain a relatively large number of subjects per group to test the main hypotheses.

\section{RESULTS}

The overall results of the experiment are summarized in Figure 1, which gives the performance on the two memory tests as a function of age, learning condition, and 

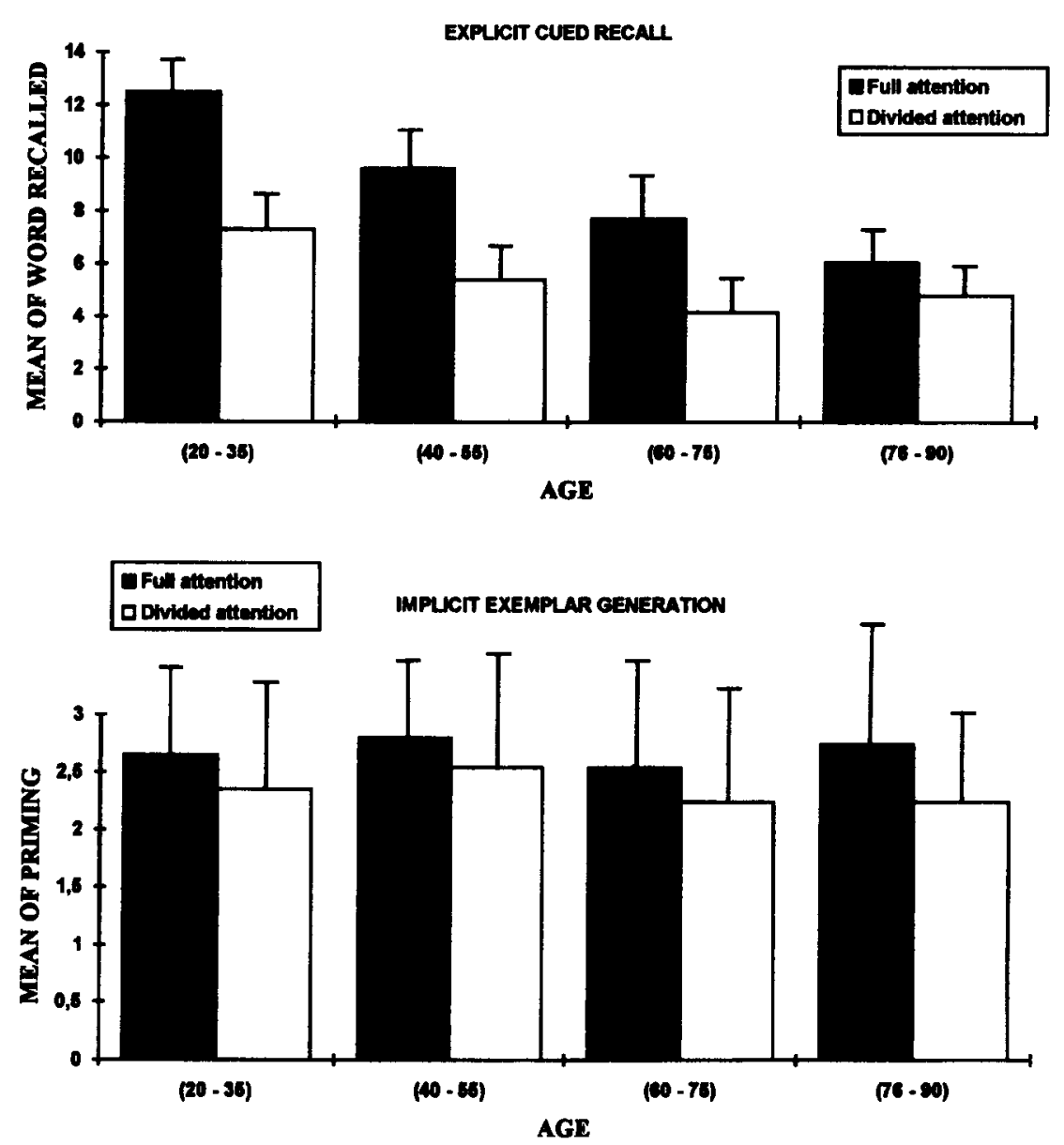

Figure 1. Mean scores (with standard errors) of word recalled (cued recall) and of priming effect (CEG) as a function of age and type of learning.

type of test. The data from the cued recall and CEG tasks are shown in the upper and lower panels of Figure 1, respectively.

The data indicate that young adults were more successful than elderly adults in recalling study list words. However, this difference did not appear in the exemplar generation test. Furthermore, performance on cued recall was affected more by the divided attention condition than it was on the priming test.

The results of the ANOVA on the cued recall score showed a significant main effect of age $[F(3,152)=$ $\left.26.72, M S_{\mathrm{e}}=6.02, p<.001\right]$, revealing a decrease in performance with age, and a significant effect of learning condition (full vs. divided attention) $[F(1,152)=$ $\left.83.14, M S_{\mathrm{e}}=6.02, p<.001\right]$, indicating a decrease in the number of words recalled in the divided attention condition. In cued recall results, there was a significant interaction between age and learning condition $[F(3,152)=$ $\left.4.79, M S_{\mathrm{e}}=6.02, p<.005\right]$, showing that the performance of the elderly subjects was less affected by the divided attention condition than was the performance of young subjects. This result can probably be explained by the fact that the elderly subjects got less involved in the consonant detection task, as testified by the significant age effect on the number of detected letters.

In the exemplar generation test, the magnitude of the priming effect was determined by comparing the number of targets produced from the study list with the number of category members produced from the unstudied list. The data showed that, for all 8 groups, there were significantly more targets produced than unprimed words. All $t$ tests were significant at $p<.001$. The mean baseline values for generation of members of the unstudied list were nearly identical across all groups and were not reliable across age $\left[F(3,152)<1, M S_{\mathrm{e}}=0.63\right]$ or across type of learning condition $[F(1,152)<1$, $\left.M S_{\mathrm{e}}=0.63\right]$. In the exemplar generation test, an ANOVA calculated on priming effect (targets produced minus baseline) revealed that neither the main effect of age $\left[F(3,152)<1, M S_{\mathrm{e}}=1.78\right]$ nor that of learning condition $\left[F(1,152)=2.55, M S_{\mathrm{e}}=1.78\right]$ was significant. Furthermore, there were no significant interactions between these two factors $\left[F(3,152)<1, M S_{\mathrm{e}}=1.78\right]$.

The above analysis of the data for each type of test was well supported by the results of an overall ANOVA including age, type of learning, and type of memory test, 
calculated for the number of target words correctly produced in the CEG test and on the number of correctly recalled targets. This analysis yielded two significant interactions: between age and type of test $[F(3,152)=$ $\left.18.52, M S_{\mathrm{e}}=4.07, p<.001\right]$, and between type of learning condition and type of test $\left[F(1,152)=51.44, M S_{\mathrm{e}}=\right.$ $4.07, p<.001]$. These two reliable interactions confirm that age and divided attention during learning have different effects on cued recall and CEG.

\section{DISCUSSION}

The major feature of interest in the present experiment was that it examined the way in which CEG and cued recall were affected by age and divided attention during learning. The results show that both aging and divided attention produced large declines in explicit cued recall but left the implicit conceptual task of CEG unchanged. Such data do not confirm the hypothesis that the CEG task may be, for the same reason that an explicit task relies on semantic-elaboration processing, similarly dependent on the allocation of attention. Because, as Craik (1986) contends, cognitive resources decrease with age, and because a dual-task condition also induces a decrease in attention, aging and divided attention were assumed to produce significant effects in both the CEG task and the explicit cued recall task.

With regard to aging, our data confirmed the results reported by Light and Albertson (1989) and extended them to include late adulthood. Such a finding seems to provide good support for the general assumption that explicit memory performance is particularly sensitive to the effect of age, whereas priming effects in implicit memory tests are not vulnerable, whether the form of priming taken into consideration is perceptual or conceptual (Light \& La Voie, 1993). Moreover, the lack of an effect of divided attention during learning is also consistent with the conclusions drawn from performance on implicit perceptual tests (Parkin et al., 1990; Parkin \& Russo, 1990; Smith \& Oscar-Breman, 1990).

The finding that explicit tasks and implicit conceptual tasks are affected differently by aging and divided attention may suggest that, although conceptual priming requires substantial semantic processing of the to-beprimed items, this processing makes fewer demands on cognitive resources than does the semantic-elaboration processing that occurs in explicit tasks. This assumption seems to provide support for claims that these two kinds of memory task are mediated by different processes.

In conclusion, it is interesting to note that the data from experiments on conceptual priming have revealed that these tests share differences and similarities with both explicit memory tasks and implicit perceptual tests. Cabeza and Ohta (1993) showed that implicit conceptual tests (e.g., category association) was stochastically independent from both explicit recognition and implicit perceptual priming tests (e.g., fragment completion). However, like explicit tasks, conceptual priming appears to be sensitive to conceptual manipulations (level of pro- cessing, generation, organization) (Hamann, 1990; Rappold \& Hashtroudi, 1991; Srinivas \& Roediger, 1990) and exhibits a pattern of results similar to that of perceptual priming tasks with amnesic patients (Gardner et al., 1973; Graf, Shimamura, \& Squire, 1985; Schacter, 1985; Shimamura \& Squire, 1984). These findings indicate that the status of conceptual priming in the classification of memory tasks needs to be clarified. Our data contribute to this issue by showing that, like perceptual priming but unlike explicit memory tasks, conceptual repetition priming can be unaffected by age and divided attention.

\section{REFERENCES}

Cabeza, R., \& OHTA, N. (1993). Dissociating conceptual priming, perceptual priming and explicit memory. European Journal of Cognitive Psychology, 5, 35-53.

Craik, F. I. M. (1977). Age differences in human memory. In J. E. Birren \& K. W. Schaie (Eds.), Handbook of the psychology of aging (pp. 384-420). New York: Van Nostrand Reinhold.

CraIK, F. I. M. (1986). A functional account of age differences in memory. In F. Klix \& H. Hagendorf (Eds.), Human memory and cognitive capabilities (pp. 409-422). Amsterdam: Elsevier.

Craik, F. I. M., \& Byrd, M. (1982). Aging and cognitive deficits: The role of attentional resources. In F. I. M. Craik \& S. Trehub (Eds.), Aging and cognitive processes (pp. 191-211). New York: Plenum.

EYSENCK, M. W. (1974). Age differences in incidental learning. Developmental Psychology, 10, 936-941.

Gardner, H., Boller, F., Moreines, J., \& Butters, N. (1973). Retrieving information from Korsakoff patients: Effects of categorical cues and reference to the task. Cortex, 9, 165-175.

GRAF, P., \& MANDLER, G. (1984). Activation makes words more accessible, but not necessarily more retrievable. Journal of Verbal Learning \& Verbal Behavior, 23, 553-568.

Graf, P., Shimamura, A. P., \& SQuire, L. R. (1985). Priming actoss modalities and across category levels: Extending the domain of preserved function in amnesia. Journal of Experimental Psychology: Learning, Memory, \& Cognition, 11, 385-395.

Grober, E., Girtin, H. L., BANG, S., \& BusChKe, M. (1992). Implicit and explicit memory in young, old and demented adults. Journal of Clinical \& Experimental Neuropsychology, 14, 298-316.

HamanN, S. B. (1990). Level-of-processing effects in conceptually driven implicit tasks. Journal of Experimental Psychology: Learning, Memory, \& Cognition, 16, 970-977.

HASHER, L., \& ZACKs, R.T. (1979). Automatic and effortful processes in memory. Journal of Experimental Psychology: General, 108, 356-388.

JACOBY, L. L., \& DaLlaS, M. (1981). On the relationship between autobiographical memory and perceptual learning. Journal of Experimental Psychology: General, 110, 306-340.

JACOBY, L. L., \& WITHERSPOON, D. (1982). Remembering without awareness. Canadian Journal of Psychology, 36, 300-324.

JaVA, R. I., \& Gardiner, J. M. (1991). Priming and aging: Further evidence of preserved memory function. American Journal of Psychology, 104, 89-100.

Light, L. L., \& AlberTson, S. A. (1989). Direct and indirect tests of memory for category exemplars in young and older adults. Psychology \& Aging, 4, 487-492.

Light, L. L., \& LA VoIE, D. (1993). Direct and indirect measures of memory in old age. In P. Graf \& M. E. J. Masson (Eds.), Implicit memory: New directions in cognition, development and neuropsychology (pp. 207-230). Hillsdale, NJ: Erlbaum.

LIGHT, L. L., \& SINGH, A. (1987). Implicit and explicit memory in young and older adults. Journal of Experimental Psychology: Learning, Memory, \& Cognition, 13, 531-541.

LigHT, L. L., Singh, A., \& CAPPS, J. L. (1986). Dissociation of memory and awareness in young and older adults. Journal of Clinical \& Experimental Neuropsychology, 8, 62-74. 
Mitchell, D. B. (1989). How many memory systems? Evidence from aging. Journal of Experimental Psychology: Learning, Memory, \& Cognition, 15, 31-49.

Mitchell, D. B., Brown, A. S., \& MurPhy, D. R. (1990). Dissociations between procedural and episodic memory: Effects of time and aging. Psychology \& Aging, 5, 264-276.

Moscovitch, M. (1982). A neuropsychological approach to perception and memory in normal and pathological aging. In F. I. M. Craik \& S. Trehub (Eds.), Aging and cognitive processes (pp. 55-76). New York: Plenum.

Moscovitch, M., Winocur, G., \& McLaChlan, D. (1986). Memory as assessed by recognition and reading time in normal and memoryimpaired people with Alzheimer's disease and other neurological disorders. Journal of Experimental Psychology: General, 115, 331347.

Parkin, A. J., Reid, T. K., \& Russo, R. (1990). On the differential nature of implicit and explicit memory. Memory \& Cognition, 18, 507514.

PARKIN, A. J., \& Russo, R. (1990). Implicit and explicit memory and the automatic/effortful distinction. European Journal of Cognitive Psychology, 2, 71-80.

RAPPOLD, V. A., \& HASHTROUdI, S. (1991). Does organization improve priming? Journal of Experimental Psychology: Learning, Memory, \& Cognition, 17, 103-114.

RiCHARDSON-KLAVEHN, A., \& BJORK, R. A. (1988). Measures of memory. Annual Review of Psychology, 39, 475-543.

Roediger, H. L., III \& BlaxtoN, T. A. (1987). Effects of varying modality, surface features, and retention interval on priming in word fragment completion. Memory \& Cognition, 15, 379-388.

Roediger, H. L., III, Weldon, M. S., \& Challis, B. H. (1989). Explaining dissociations between implicit and explicit measures of retention: A processing account. In H. L. Roediger III \& F. I. M. Craik (Eds.), Varieties of memory and consciousness: Essays in honor of Endel Tulving (pp. 3-36). Hillsdale, NJ: Erlbaum.
Scarborough, D. L., Cortese, C., \& Scarborough, H. S. (1977) Frequency and repetition effects in lexical memory. Journal of Experimental Psychology: Learning, Memory, \& Cognition, 3, 1-17.

SCHACTER, D. L. (1985). Priming of old and new knowledge in amnesic patients and normal subjects. In D. S. Olton, E. Gamzu, \& S. Corkin (Eds.), Memory dysfunctions: An integration of animal and human research from preclinical and clinical perspectives (Annals of the New York Academy of Sciences, Vol. 444, pp. 41-53). New York: New York Academy of Sciences.

SCHACTER, D. L. (1987). Implicit memory: History and current status. Journal of Experimental Psychology: Learning, Memory, \& Cognition, 13, 501-518.

Shimamura, A. P., \& Seuire, L. R. (1984). Paired-associate learning and priming effects in amnesia: A neuropsychological study. Journal of Experimental Psychology: General, 113, 556-570.

SMith, M. E., \& OsCar-Berman, M. (1990). Repetition priming of words and pseudowords in divided attention and in amnesia. Journal of Experimental Psychology: Learning, Memory, \& Cognition, 16, 1033-1042.

Srinivas, K., \& Roediger, H. L., III (1990). Classifying implicit memory tests: Category association and anagram solution. Journal of Memory \& Language, 29, 389-412.

TOURETTE, G. (1979). Tables catégorielles: Normes de production de 30 catégories sémantiques. Poitiers, France: Laboratoire de Psychologie de l'Université de Poitiers.

Tulving, E., Schacter, D. L., \& Stark, H. A. (1982). Priming effects in word-fragment completion are independent of recognition memory. Journal of Experimental Psychology: Learning, Memory, \& Cognition, 8, 336-342.

WARRINGTON, E. K., \& WeIskranTZ, L. (1970). Amnesia : Consolidation or retrieval? Nature, 228, 628-630.

(Manuscript received December 28, 1993; revision accepted for publication August 8, 1994.) 